Authors: Gilbert RE, Mok Q, Dwan K, Harron K, Moitt T, Millar M, Ramnarayan P, Tibby S, Hughes D,

\begin{tabular}{|c|c|}
\hline Ruth Gilbert MD & $\begin{array}{l}\text { Professor of Clinical Epidemiology, UCL Institute of Child Health, } 30 \\
\text { Guilford St, London, WC1N 1EH. R.gilbert@ucl.ac.uk, Tel: } \\
\text { +442079052101 Fax:+442079052793 }\end{array}$ \\
\hline Quen Mok FRCP & $\begin{array}{l}\text { Consultant in Paediatric Intensive Care, Great Ormond Street } \\
\text { Hospital for Children. Quen.Mok@gosh.nhs.uk }\end{array}$ \\
\hline Kerry Dwan PhD & $\begin{array}{l}\text { Research Associate, Department of Biostatistics, University of } \\
\text { Liverpool. Kerry.Dwan@liverpool.ac.uk }\end{array}$ \\
\hline Katie Harron PhD & $\begin{array}{l}\text { Research Fellow, UCL Institute of Child Health, London. } \\
\text { k.harron@ucl.ac.uk }\end{array}$ \\
\hline Tracy Moitt & $\begin{array}{l}\text { Senior Trials Manager, Medicines for Children Clinical Trials Unit, } \\
\text { University of Liverpool. tracyb@liverpool.ac.uk }\end{array}$ \\
\hline Mike Millar PhD, FRCPath & $\begin{array}{l}\text { Consultant in Infection, Barts Health NHS Trust (Honorary Professor, } \\
\text { Queen Mary, University of London. } \\
\text { Michael.Millar@bartshealth.nhs.uk, }\end{array}$ \\
\hline $\begin{array}{l}\text { Padmanabhan } \\
\text { Ramnarayan MD }\end{array}$ & $\begin{array}{l}\text { Consultant in Paediatric Intensive Care and Retrieval, Children's } \\
\text { Acute Transport Service, Great Ormond Street Hospital for Children, } \\
\text { London. ramnap@gosh.nhs.uk, }\end{array}$ \\
\hline Shane M Tibby MB ChB & $\begin{array}{l}\text { Consultant in Paediatric Intensive Care, Evelina Children's Hospital, } \\
\text { London. Shane.Tibby@gstt.nhs.uk }\end{array}$ \\
\hline Dyfrig Hughes PhD & $\begin{array}{l}\text { Professor of Pharmacoeconomics, Centre for Health Economics \& } \\
\text { Medicines Evaluation, Bangor University. D.a.hughes@bangor.ac.uk, }\end{array}$ \\
\hline
\end{tabular}




\begin{tabular}{|l|l|}
\hline Carrol Gamble PhD & $\begin{array}{l}\text { Professor of Medical Statistics, Department of Biostatistics, } \\
\text { University of Liverpool. } \underline{\text { C.Gamble@liverpool.ac.uk }}\end{array}$ \\
\hline
\end{tabular}

*Names and contributions given in acknowledgements

6

Word count 3721

7 Key words: randomised controlled trial, bloodstream, infection, central venous catheter, pediatric 8 intensive care, antibiotic, heparin

9 
Background: Impregnated central venous catheters (CVCs) are recommended for adults to reduce bloodstream infection (BSI) but not for children due to a lack of evidence for their effectiveness.

Methods: Randomised trial of children admitted to 14 English paediatric intensive care units (PICUs). The primary outcome, time to first BSI between 48 hours after randomisation and 48 hours after CVC removal, was compared for any impregnation (antibiotic or heparin) versus standard CVCs (primary analyses) and in pair-wise comparisons of all three CVC types (secondary analyses). Findings: BSI occurred in 3.59\% (18/502) randomised to standard CVC, 1.44\% (7/486) to antibiotic and 3.42\% (17/497) to heparin CVC. Primary analyses showed no effect of impregnated (antibiotic or heparin) compared with standard CVCs (hazard ratio for time to first BSI $0.71 ; 95 \% \mathrm{Cl} 0.37-1.34$ ) Secondary analyses showed antibiotic CVCs were superior to standard (HR $0.43 ; 0.20-0.96)$ and to heparin CVCs (HR 0.42; 0.19-0.93), but heparin did not differ from standard (HR 1.04; 0.53-2.03). Clinically important and statistically significant absolute risk differences were found only for antibiotic vs standard $(-2.15 \% ; 95 \% \mathrm{Cl}:-4.09,-0.20 ;$ number needed to treat $=47 ; 95 \% \mathrm{Cl}: 25,500)$ and antibiotic vs heparin CVCs $(-1.98 \% ;-3.90,-0.06 ; \mathrm{NNT}=51 ; 26,1667)$. Time to thrombosis, mortality by 30 days, and minocycline or rifampicin resistance, did not differ by CVC allocation. Interpretation: Antibiotic-impregnated CVCs significantly reduced the risk of BSI compared with standard and heparin CVCs. Widespread adoption of antibiotic-impregnated CVCs could help prevent BSI in PICU.

Funding: UK National Institute for Health Research. 
Bloodstream infections (BSI) are important causes of adverse clinical outcomes and costs to health services. Paediatric intensive care units (PICUs) have one of the highest reported rates of hospitalacquired BSI of any clinical specialty with central venous catheters (CVCs) being a frequent cause of BSI in PICU. ${ }^{1,2}$ US studies report the success of improved aseptic practices during insertion and maintenance of CVCs for reducing rates of catheter-related BSI (CR-BSI). ${ }^{3-5}$ The UK Department of Health invested in similar infection reduction initiatives, including the Saving Lives CVC care bundle and the Matching Michigan scheme. ${ }^{6-8}$

40

Use of CVCs that are impregnated, for example with antibiotics, chlorhexidine or heparin, has been recommended as part of these infection reduction initiatives in the US and UK, but only for adults at high risk of BSI. ${ }^{7,9}$ Impregnated CVCs have not been recommended for children. ${ }^{10}$ The evidence for reduced rates of CR-BSI with impregnated compared with standard CVCs derives from trials predominantly of adults. Recent systematic reviews draw on evidence from 56 randomised controlled trials (RCT). ${ }^{11-14} \mathrm{~A}$ network meta-analysis of direct and indirect comparisons of impregnated and standard CVCs found that heparin-bonded or antibiotic-impregnated CVCs were the most effective options, with an associated $70 \%-80 \%$ reduction in the risk of CR-BSI. ${ }^{14}$

Despite the large number of randomised controlled trials, there is relatively weak evidence to guide policy about adoption of impregnated CVCs for all who need them, particularly children. Firstly, there are inherent biases in the use of CR-BSI - the primary outcome used in all previous trials - as this could overestimate benefits of antibiotic impregnation. ${ }^{11,15}$ CR-BSI requires positive cultures of the same organism from the CVC tip and from blood, which excludes many patients with BSI and may favour antibiotic impregnated CVC tips through inhibition of bacterial growth in culture media. ${ }^{16}$ Secondly, few studies have been conducted in the context of the low infection rates associated with improved asepsis programmes. ${ }^{6,7,17}$ Thirdly, very few trials involve children (see box on research in 
context). ${ }^{18-20}$ Compared with adults, children require narrower CVCs, which thrombose more readily.

59 Standard, non-impregnated CVCs are still used for the majority of children in UK PICUs. ${ }^{10}$ However,

60 there could be significant gains for children's health and healthcare costs if impregnated CVCs could

61 be confirmed to reduce rates of BSI.

62

63 We conducted a pragmatic, three-arm randomised controlled trial to determine the effectiveness of 64 any type of impregnation (antibiotic or heparin) compared with standard CVCs for preventing BSI in 65 children requiring intensive care. A secondary aim was to determine which of the three types of CVC 66 was most effective. We also determined the effectiveness of type of CVC on CR-BSI, duration of 67 care, and safety, including mortality and adverse events such as antibiotic resistance.

68 
Design, study population and intervention

Children admitted to 14 PICUs in England between December 2010 and November 2012 were randomised to CVCs impregnated with antibiotics or heparin or to standard CVCs. Both types of impregnation involve internal and external surfaces. We used polyurethane CVCs manufactured by Cook Medical Incorporated (IN 47404 USA). Sizes used were French gauge 4 (double lumen), 5 or 7 (triple lumen). Cook reports a concentration of $503 \mu \mathrm{g} / \mathrm{cm}$ minocycline and $480 \mu \mathrm{g} / \mathrm{cm}$ rifampicin for their antibiotic impregnated CVC, which reduces biofilm formation. ${ }^{21}$ Heparin bonding reduces thrombus and thereby biofilm formation and uses benzalkonium chloride as an anti-infective bonding agent. ${ }^{1622}$

Children $<16$ years were eligible if they were admitted or being prepared for admission to a participating PICU and were expected to require a CVC for 3 or more days. For children admitted to PICU following elective surgery, we sought prospective parental consent during pre-operative assessment. For children who required a CVC as an emergency, we sought parental consent after randomisation and stabilisation (deferred consent) to avoid delaying treatment. Parents consented to the use of their child's data for the trial, to follow-up using routinely recorded clinical data, and to an additional $0.5 \mathrm{ml}$ of blood being collected for PCR testing whenever a blood culture was clinically required. Further details are given in the protocol (see supplementary material).

\section{Randomisation and masking}

Children were randomised at the bedside or in theatre (operating room) immediately prior to CVC insertion. The clinician or research nurse opened a pressure sealed, sequentially numbered, opaque envelope containing the CVC allocation. Randomisation sequences were computer generated in a 
consent, site and envelope storage location within the site to facilitate easy access to envelopes (e.g. for insertion in theatre and in PICU).

CVC allocation was not blinded to the clinician responsible for inserting the CVC (due to different colour strips for antibiotic and heparin CVCs) but since CVCs looked identical whilst in situ, allocation was concealed from patients, their parents and PICU personnel responsible for their care. Labels identifying the type of CVC were held securely in a locked drawer in case unblinding was required. Participant inclusion in analyses and occurrence of outcome events were established prior to release of the randomisation sequence for analysis and for the data monitoring committee.

\section{Comparisons and end points}

The primary analysis for the trial compared any impregnated CVCs (antibiotic or heparin) with standard CVCs. Secondary analyses involved pair-wise comparisons for the three types of CVC.

The primary outcome was time to the first BSI based on blood cultures taken between 48 hours after randomisation and 48 hours after $\mathrm{CVC}$ removal (or prior to death). All blood culture samples included in the primary outcome were clinically indicated, defined by recorded evidence of infection (one or more of: temperature instability, change in inotrope requirements, haemodynamic instability, or poor perfusion) or removal of the CVC due to suspected infection. Blood cultures were recorded as positive for the primary outcome if any organism was isolated that was not a skin commensal or if coagulasenegative staphylococci (or other skin commensals) were isolated and there were two or more positive cultures of the same organism within 48 hours of each other. A clinical committee reviewed all primary outcomes involving positive cultures without knowledge of CVC allocation status. A sensitivity analysis assumed that the primary outcome occurred for those with a record of clinical indication but no blood culture taken in the primary outcome time window. 

and CVC tip between 48 hours after randomization and 48 hours after CVC removal; or differential positivity of cultures from multiple CVC lumens on two or more occasions; or exit site infection or CVC removed for infection; (2) rate of BSI per 1000 CVC-days: based on one or more BSI between randomisation and CVC removal; and (3) time to a composite measure of BSI comprising the primary outcome or a negative blood culture combined with a positive 16S PCR result for bacterial DNA, removal of the CVC because of suspected infection, or a start of antibiotics or change in type of antibiotics on the same or next day.

Other secondary outcomes included time to CVC removal and time to CVC thrombosis (defined by two episodes within five days of each other of difficulty flushing the CVC or drawing back blood from the CVC, one episode of swollen limb, CVC removal due to thrombosis, or a positive ultrasound indicating thrombosis). We also compared the time to PICU discharge, hospital discharge, and death within 30 days of randomisation. Deaths were recorded by the research team and/or by linkage to death certification data from the Office of National Statistics. Cost-effectiveness analyses based on linked hospital resource data for six-months follow-up will be reported elsewhere.

Safety analyses compared CVC-related adverse events (including unexplained thrombocytopenia after insertion of CVC), mortality, and antibiotic resistance to minocycline ( $>0.5 \mu \mathrm{g} / \mathrm{ml})$ or rifampicin $(>1.0 \mu \mathrm{g} / \mathrm{ml}$ ) based on etest strips applied to organisms isolated from BSI (www.biomerieuxdiagnostics.com/etest). Incomplete laboratory testing and reporting limited analyses of resistance in positive blood cultures and prevented analysis of resistance in cultures from the CVC tip (as specified in the protocol). 
Participation in the trial did not involve any changes to standard clinical care or data collection apart

from collecting an additional $0.5 \mathrm{ml}$ of blood whenever a blood culture sample was taken. The sample was sent for PCR testing for 16S rRNA of bacterial ribosome protein to detect bacterial infection. We sought consent to link data from hospital administrative records for six months after randomisation and from the national Paediatric Intensive Care Audit Network (PICANet ${ }^{23}$ ) to the child's study data to categorise the primary reason for admission and the Paediatric Index of Mortality score on admission (PIM2 ${ }^{24}$ ).

\section{Sample size}

We based the sample size calculation for the primary analysis on a relative risk (RR). We assumed detection of a RR of 0.5 in patients with a baseline risk of $10 \%$ would change policy. We assumed the RR would remain relatively constant across baseline risks while the absolute risk difference would be more variable. 1200 children in a 2:1 ratio (impregnated:standard) were required to achieve $80 \%$ power to detect a RR of 0.5 at a $5 \%$ level of significance, based on an estimated BSI rate of $10 \%$ and allowing for $5 \%$ loss to follow-up. A lower than expected BSI rate of $5 \%$ would have $62 \%$ power to detect a RR of 0.5 or $80 \%$ power for a RR of 0.32 .

161

The Independent Data Monitoring Committee recommended continuation of the study until 30 November 2012 after: reviewing the first 209 children; an interim analysis of 650 children using the Peto-Haybittle stopping rule for the primary outcome; recruitment had reached the original target of 1200 pre-schedule in June 2012 and there were no safety concerns. The recommendation for continuation aimed to exhaust available funding.

\section{Statistical analysis}

Outcome data were analysed according to the intention to treat principle. Safety analyses included the subset of children for whom CVC insertion was attempted, grouped by CVC actually received. 
171 The statistical analysis plan was developed prior to analysis and is available in the supplementary material. The full statistical report is available from the authors. A $5 \%$ level of statistical significance and $95 \%$ confidence intervals were used throughout. Absolute risk differences were calculated for proportions. Time to event outcomes were analysed using Kaplan-Meier curves and the log-rank test. Cox regression was used to adjust primary and secondary analyses of time to first BSI for prospective or deferred consent type and suspected infection at baseline. In a post-hoc, sensitivity analysis, we used cumulative incidence curves to evaluate competing risks from death for time to first bloodstream infection. We applied Gray's test to detect whether there was a difference between impregnated and standard CVCs for the primary outcome. ${ }^{25}$ For secondary outcomes, binary outcomes were analysed using the chi squared test and continuous outcomes analysed using the Mann Whitney $U$ test. The rate of BSI (defined as the total number of BSI per 1000 CVC-days occurring between randomisation and CVC removal) was analysed using Poisson regression. All analyses were conducted using SAS software version 9.2.

\section{Study oversight and role of funders}

The Research Ethics Committee for South West England approved the study protocol (reference number 09/H0206/69). The manufacturer Cook supplied CVCs to participating units at a $20 \%$ discounted price. Neither the manufacturer nor the funder (the National Institute of Health Research) had any role in the design of the study, collection or interpretation of data or reporting of results. The CATCH trial is registered with ClinicalTrials.gov (Identifier:NCT01029717). The protocol and Statistical Analysis Plan are available as supplementary files and at http://www.nets.nihr.ac.uk/projects/hta/081347. The full statistical analysis report is available on request from the authors. 


\section{Study population}

Overall, 1859 children were randomised (501 prospective, 1358 emergency). However, 984/1358

(72\%) emergency patients subsequently provided deferred consent, leaving 1485 participants for final analysis (Figure 1). Reasons for non-consent are reported in Figure 1. Of the 1485 randomised participants, 75 (5\%) did not receive a CVC: in 53 insertion was attempted but unsuccessful and in 22 CVC insertion was not attempted ( 16 no longer required, 5 reason not known and 1 patient died). Of those receiving a CVC, more of those randomised to standard CVC received the allocated type of CVC (93\%; 468/502 allocated to standard; $90 \% ; 437 / 486$ to antibiotic, and $89 \% ; 440 / 497$ to heparin; Figure 1). The majority of CVCs received but not allocated CVCs were standard CVCs (69\%; 45/65; Figure 1). All randomised and consented participants were followed up until 48 hours after CVC removal or attempted CVC insertion.

208

\section{Baseline characteristics}

Table 1 shows that over half (58\%) of children were aged under 12 months at admission, with onethird aged less than 3 months. One third of children had surgery prior to admission to PICU and half had cardiovascular problems as their primary diagnosis at admission. CVC insertion took place in the operating room for $437 / 493$ (89\%) in the prospective consent (elective) group, but in only $34 / 917$ (4\%) of the deferred consent (emergency) group

\section{Endpoints}

Primary outcome

Clinical indicators of infection were recorded during the primary outcome time interval from 48 hours after randomisation up to 48 hours after CVC removal for 610/1485 (41\%) participants, most of whom (593/610; 97\%) had blood cultures taken (Figure 1). Derivation of the primary outcome and the number of BSI excluded from the primary outcome is shown in supplementary Figure 1 . The 
primary outcome of BSI was recorded for 42 children: standard 18/502 (3.6\%); antibiotic 7/486

(1.4\%); heparin 17/497 (3.4\%). Gram positive organisms accounted for the majority of BSI (23/42; $55 \%)$ of which $6(14 \%)$ were positive for coagulase negative staphylococci (Table 2). Details of all organisms isolated in the primary outcomes are given in supplementary Table 1. All outcomes are reported by CVC type in Table 2.

227

In the primary comparison, time to BSI did not differ between impregnated CVCs (antibiotic or heparin combined) and standard CVCs (Hazard ratio $0.74 ; 95 \% \mathrm{Cl}: 0.37,1.34$; Table 3 ). In secondary, pair-wise comparisons, antibiotic impregnated CVCs reduced the risk of BSI compared with standard CVCs (HR 0.43; 0.20, 0.96) and compared with heparin CVCs (HR 0.42; 0.19, 0.93). Absolute risks of BSI differed significantly at the $5 \%$ level only for antibiotic CVCs compared with standard $(-2.15 \%)$ and heparin CVCs (-1.98\%; Table 3).

Figure 2 shows the Kaplan-Meier curve for time to first BSI. There was no significant difference in time to first BSI comparing any impregnated CVC with standard $(p=0.29)$ or heparin with standard $(p=0.90)$. BSI risk was reduced for antibiotic compared with standard CVCs $(p=0.04)$ and for antibiotic compared with heparin CVCs $(p=0.03)$. The direction of these results was robust to the sensitivity analysis in which the 17 cases with clinical indicators but no blood culture taken were assumed to have a positive BSI (supplementary appendix Table A2). The direction of results did not change in the regression analysis (supplementary appendix Table A3). Competing risks analyses using Gray's test indicated no difference between impregnated compared with standard CVCs for either competing risks ( $p$-values of $p=0.29$ for bloodstream infection and $p=0.89$ for death).

Secondary outcomes

There was no significant difference between any impregnated and standard CVCs $(p=0.13)$ in the risk of CR-BSI. The risk of CR-BSI was significantly lower for antibiotic vs standard CVC ( $p=0.03)$ and for 
antibiotic vs heparin CVCs ( $p=0.09$; Table 3 ). The BSI rate per 1000 CVC-days was lowest in the antibiotic group (Table 2). No children had more than one BSI whilst the trial CVC was in place. The inter-relationship between outcomes involving BSI is shown by time since randomisation in supplementary appendix Figure 2. The composite measure of BSI or culture negative infection did not differ by CVC (Tables 2 and 3). Supplementary Table A4 shows indicators of infection contributing to the composite measure. No other secondary outcomes were associated with type of CVC (Table 3).

\section{Safety}

The cohort for safety (per protocol) analyses were based on children who had a CVC insertion attempted. These analyses comprised more children in the standard group $(n=533)$ than the antibiotic ( $n=451)$ or heparin groups ( $n=479$; Table 2; see statistical analysis plan section 11$)$. No CVC-related adverse events ( 31 events) or mortality (148 events) were attributed to type of CVC received (Table 2). Two children developed thrombocytopenia unrelated to the type of CVC. One was allocated to antibiotic and the other to heparin CVC (full statistical analysis report available from the authors).

Testing for antibiotic resistance varied by centre. Only 12 of the 42 children with the primary outcome BSI had minocycline and rifampicin resistance reported using etest strips; 8/12 were resistant to one or both antibiotics ( $3 / 5$ standard; $2 / 2$ antibiotic; $3 / 5$ heparin; supplementary Table 5). Most resistance occurred in gram negative organisms (7/9 organisms cultured from 8 BSI episodes; Table A5). Resistance was detected in two BSI that were positive for staphylococcal species: one allocated to antibiotic and the other to heparin CVC (supplementary appendix Table A5). 
Impregnated CVCs are not recommended for use in children because of the lack of clear evidence of their effectiveness. In this first trial to compare two types of impregnated CVCs with standard CVCs in children our primary analysis showed no evidence of a statistically significant difference between time to first BSI for any impregnated CVCs (antibiotic and heparin combined) compared with standard CVCs. However, antibiotic impregnation reduced the risk of BSI by $57 \%$ compared with standard CVCs, and by 58\% compared with heparin-bonded CVCs. Antibiotic-impregnated CVCs were associated with an absolute risk reduction of $2.15 \%$ compared with standard CVCs, meaning 47 children $(95 \% \mathrm{Cl}: 25,500)$ would need to be treated with an antibiotic-impregnated CVC instead of a standard CVC to prevent one case of BSI.

Strengths of the study include the use of any BSI as a clinically important primary outcome thereby avoiding the biases inherent in measuring CR-BSI. A further strength was the restriction to positive blood cultures that were clinically indicated, thereby recording an outcome that clinicians would regard as potentially serious and needing treatment. Restriction to clinically indicated blood cultures increased the clinical relevance of the primary outcome, but, in contrast to routine blood culture sampling for all study participants, diminished the sensitivity of the study to detect bacteraemia. Only $41 \%$ of children had clinical indicators of blood stream infection recorded during the primary outcome interval but nearly all of these had a blood culture taken. A third strength is the representativeness of the study population in terms of children admitted to the 14 largest PICUs (out of a total of 24) across the country. We were able to enrol a similar proportion of emergency patients (two-thirds) as seen in practice, ${ }^{26}$ enabled by the inclusion of retrieved children and the use of deferred consent.

Limitations include the limited power of the study to detect differences in the primary outcome according to the type of CVC. The trial was based on the best available evidence at the time, which 
indicated large but equivalent benefits of antibiotic and heparin CVCs compared with standard. The key question, which determined our primary analysis and sample size, was whether these benefits occurred in children. Secondary, pair-wise comparisons addressed which type of impregnated CVC was best, but the trial was not adequately powered to detect the anticipated small differences between antibiotic and heparin CVCs. Power was further eroded by the low baseline rate of BSI.

304 factors, thereby biasing towards the null effect. measure adequately. 
Lack of blinding was another limitation, although we found no evidence of differential blood culture sampling by trial arm (Figure 1). The number of children who received their allocated CVC was slightly higher for those in the standard arm, probably reflecting the fact that standard CVCs were the default CVC used in many units. ${ }^{10}$ Lastly, antibiotic resistance testing using etest strips was not done for all positive blood cultures. This reflects local laboratory administration and processing, which centralised testing of positive cultures could have mitigated. Where reported, resistance occurred in all trial arms, predominantly in gram negative isolates, as expected. The low rates are consistent with previous lack of evidence for the emergence of resistance. ${ }^{27}$

\section{Implications}

The primary outcome, time to BSI, did not differ between impregnated and standard CVCs. However, secondary, pair-wise analyses of the type of CVC, showed that only antibiotic CVC reduced the risk of BSI compared with standard and with heparin CVCs. The low rate of BSI in the standard and heparin groups and the multiple, pair-wise comparisons, reduced the power of our study. However, when combined with evidence from systematic reviews, our findings establish the effectiveness of antibiotic-impregnated CVCs compared with standard CVCs and extend this evidence for paediatric use. For the first time we directly demonstrate effectiveness of antibiotic CVCs compared with heparin-bonded CVCs in this population, even in the context of low rates of BSI. Widespread adoption of antibiotic-impregnated CVCs could help prevent BSI in PICU. Whether these benefits outweigh the additional costs depends on differential pricing of antibiotic and standard CVCs by the manufacturer and the cost benefits of avoiding bloodstream infection. 
We searched PubMed, initially for systematic reviews or meta-analyses, using the clinical queries filter for therapy studies or terms for meta-analysis and (catheter* OR central OR venous OR intravenous) (impregnated $O R$ bonded $O R$ coated $O R$ antibiotic $O R$ heparin) and infection. We found 5 systematic reviews published since 2008. The two most recent reviews were both published in the Cochrane Library. One included any type of CVC impregnation, but excluded children ( 56 RCTs, 5 antibiotic vs standard; 1 heparin vs standard). ${ }^{13}$ The other compared heparin bonded with standard CVCs in children ( 2 trials). ${ }^{28}$ All the trials evaluated in these two reviews were included in an earlier systematic review and network meta-analysis by Wang et al which comprised direct and indirect mixed treatment comparisons of 45 RCTs evaluating CR-BSI ( 6 antibiotic vs standard none in children; 3 heparin vs standard, 2 in children). For antibiotic (minocycline-rifampicin) compared with standard CVC, Wang et al reported a pooled odds ratio for CR-BSI of $0.18(95 \% \mathrm{Cl} ; 0.08,0.34) .{ }^{14}$ We found one subsequent randomised controlled trial which compared antibiotic (minocycline and rifampicin) and standard CVCs for children undergoing heart surgery. ${ }^{19}$ The trial of 288 participants was terminated early because of a low event rate ( 3 catheter associated BSI in each group). The mixed treatment comparison for heparin-bonded vs standard CVCs produced a pooled odds ratio of $0.20(0.06,0.44)$, and for antibiotic compared with heparin CVCs (indirect comparisons only), OR $1.18(0.28,3.29) .{ }^{14}$ A previous cost-effectiveness analysis based on trials in adults estimated that impregnated CVCs would be cost effective even at baseline risks of $\mathrm{BSI}$ as low as $0.2 \% .^{12}$

\section{Added value of this study}

This is the first trial to evaluate antibiotic and heparin CVCs in children and in the context of low BSI rates associated with improved asepsis practices. We add new evidence of effectiveness of antibiotic CVCs for any $\mathrm{BSI}$, showing a 57\% reduction compared with standard CVCs in children. We confirmed the effectiveness of antibiotic CVCs found in systematic reviews of trials in adults, with a 75\% reduction in the risk of CR-BSI (HR 25; $0.07,0.90)$ compared with standard CVCs, for the first time in children. We also report for the first time that antibiotic CVCs are superior to heparin CVCs. These results are based on secondary analyses so need to be interpreted with caution. Our results are consistent with previous studies showing no effect of antibiotic impregnation on mortality or adverse effects.

In contrast to evidence from systematic reviews, we found no significant effect for heparin bonded vs standard CVCs. The lack of effectiveness of heparin CVCs may relate to the low baseline event rate observed in CATCH, which was conducted after implementation of CVC care bundles in PICUs to improve asepsis procedures during CVC insertion and maintenance. ${ }^{10,29}$ Another potential explanation could be emergence of resistance to benzalkonium chloride, the bonding agent used for heparin, which is widely used in hand hygiene products.

\section{Implications of the available evidence}

When combined with previous systematic reviews, our findings establish the effectiveness of antibioticimpregnated CVCs compared with standard CVCs and extend this evidence for paediatric use. Widespread adoption of antibiotic-impregnated CVCs could help prevent BSI in PICUs. 


\section{Contributions}

All authors contributed to the design and/or conduct of the study. RG (chief investigator), QM and CG conceived and designed the study. Statistical analyses were conducted by Kerry Dwan and Carrol Gamble. End point review for the primary outcome was done by QM, MM and RG. RG, QM, KD, KH and CG wrote the paper and all authors commented on the manuscript and approved the final version.

\section{Acknowledgements}

We thank the children and families who participated in the CATCH trial and the principal investigators and research nurses at each study site (in order of number of patients recruited): GOSH (Quen Mok, Twin Yen Lee, Samantha Riordan), Southampton General Hospital (lain Macintosh, Jenni McCorkell, Katie Stearn, Rosie Mitchell), Evelina Children's Hospital (Shane Tibby, Julia Harris, Paul Wellman), Birmingham Children's Hospital (Oliver Bagshaw, Jenna Spry, Simon Laker, Nikki Holdback), Leeds General Infirmary (John Roche, Sian Cooper, Darren Hewett), Alder Hey Children's Hospital (Steve Kerr, Felicity Haigh), Bristol Royal Hospital for Children (Michelle White, Margrid Schindler, Clare Traub, Nina Worrin), Glenfield Hospital (Raghu Ramaiah, Rekha Patel), Royal Brompton Hospital (Duncan Macrae, Sarah Bacon), St Mary's Hospital, London (Mehrengise Cooper, Amina Abdulla, Amy Brewer), Royal Victoria Infirmary (Rachel Agbeko, Christine Mackerness), Queens Medical Centre (Patrick Davies, Daniel Walsh, Lindsay Crate), Freeman Hospital (Rachel Agbeko, Clare Simmister), Leicester Royal Infirmary (Raghu Ramaiah, Rekha Patel). We thank the Local Research Networks (LRNs) in England for supporting the trial implementation; the Trial Steering Committee (Robert Tasker (chair) and Stephen Playfor (chair), Andy Vail, Derek Roebuck and Jim Gray) and the Independent Data Safety and Monitoring Committee (Paul Ewings (chair), Mike Sharland, Neena Modi) for their oversight of the study. In addition to co-authors, Colin Ridyard, Angie Wade, Liz Draper, Oliver Bagshaw, Julia Harris and Darren Hewett participated in the trial management group. Other contributors were Michaela Blundell (quality assurance checks), 
413 Susan Howlin and Lynsey Finnetty (data management), and Ivana Pribramska (administrative

414 support).

415

$416 \quad$ Funding

417 The trial was funded by the National Institute for Health Research Health Technology Assessment

418 (NIHR HTA) programme (project number 08/13/47). The views and opinions expressed therein are

419 those of the authors and do not necessarily reflect those of the HTA programme, NIHR, NHS or the

420 Department of Health. No funding was provided by the manufacturer (Cook) of the CVCs, although

421 participating units could purchase CVCs at a discount of $20 \%$ during recruitment to the study.

422 Neither the funder nor the manufacturer had any involvement in the study design, interpretation of

423 the results or writing of the report.

424 
426 1. Abou Elella R, Najm H, Balkhy H, Bullard L, Kabbani M. Impact of bloodstream infection on

427 the outcome of children undergoing cardiac surgery. Pediatr Cardiol. 2010; 31(4): 483-9.

428 2. Elward AM, Hollenbeak CS, Warren DK, Fraser VJ. Attributable cost of nosocomial primary

429 bloodstream infection in pediatric intensive care unit patients. Pediatrics. 2005; 115(4): 868-72.

430 3. Bhutta A, Gilliam C, Honeycutt M, Schexnayder S, Green J, Moss M, et al. Reduction of

431 bloodstream infections associated with catheters in paediatric intensive care unit: stepwise

432 approach. BMJ. 2007; 334(7589): 362-5.

433 4. Pronovost P, Needham D, Berenholtz S, Sinopoli D, Chu H, Cosgrove S, et al. An intervention

434 to decrease catheter-related bloodstream infections in the ICU. New Engl J Med. 2006; 355(26):

$435 \quad 2725-32$.

436 5. Miller MR, Griswold M, Harris JM, II, Yenokyan G, Huskins WC, Moss M, et al. Decreasing

437 PICU catheter-associated bloodstream infections: NACHRI's quality transformation efforts.

438 Pediatrics. 2010; 125(2): 206-13.

439 6. Bion J, Richardson A, Hibbert P, Beer J, Abrusci T, McCutcheon M, et al. 'Matching Michigan':

440 a 2-year stepped interventional programme to minimise central venous catheter-blood stream

441 infections in intensive care units in England. BMJ Qual Saf. 2012; 22(2): 110-23.

442 7. Department of Health. Saving Lives: reducing infection, delivering clean and safe care:

443 Department of Health, London 2007.

444 8. HM Treasury. Pre-budget report and comprehensive spending review. London: The

445 Stationary Office; 2007.

446 9. O'Grady NP, Alexander M, Burns LA, Dellinger EP, Garland J, Heard SO, et al. Guidelines for 447 the prevention of intravascular catheter-related infections. Clin Infect Dis. 2011; 52(9): e162-e93.

448 10. Harron K, Ramachandra G, Mok Q, Gilbert R. Consistency between guidelines and reported 449 practice for reducing the risk of catheter-related infection in British paediatric intensive care units. 450 Intens Care Med. 2011; 37(10): 1641-7. 

related blood stream infection: a systematic review. Curr Opin Infect Dis. 2008; 21(3): 235-45. and cost-effectiveness of central venous catheters treated with anti-infective agents in preventing bloodstream infections: a systematic review and economic evaluation. Health Technol Asses. 2008; 12(12): 1-154.

13. Lai NM, Chaiyakunapruk N, Lai NA, O'Riordan E, Pau WSC, Saint S. Catheter impregnation, coating or bonding for reducing central venous catheter-related infections in adults. Cochrane Database Syst Rev. 2013; 6: CD007878. venous catheters for catheter-related infections: a network meta-analysis. J Hosp Infect. 2010; 76(1): $1-11$.

15. Geffers C, Zuschneid I, Eckmanns T, Rüden H, Gastmeier P. The relationship between methodological trial quality and the effects of impregnated central venous catheters. Intens Care Med. 2003; 29(3): 403-9. antiseptic-impregnated vascular catheters. J Infect Dis. 1993; 167(4): 920-4. 17. Harron K, Parslow R, Mok Q, Tibby S, Wade A, Muller-Pebody B, et al. Monitoring quality of care through linkage of administrative data: national trends in bloodstream infection in UK paediatric intensive care units 2003-2012. Crit Care Med. 2015; in press.

472 infective complications in critically ill children. Intens Care Med. 2000; 26(7): 967-72.

473 19. Cox EG, Knoderer CA, Jennings A, Brown JW, Rodefeld MD, Walker SG, et al. A randomized, 474 controlled trial of catheter-related infectious event rates using antibiotic-impregnated catheters 475 versus conventional catheters in pediatric cardiovascular surgery patients. Pediatr Infect Dis J. 2012. 
476 20. Abdelkefi A, Achour W, Ben Othman T, Ladeb S, Torjman L, Lakhal A, et al. Use of heparin-

477 coated central venous lines to prevent catheter-related bloodstream infection. J Support Oncol.

$478 \quad 2007 ; 5(6): 273-8$.

479 21. Cook Incorporated. Cook Spectrum ${ }^{\circledR}$ Central Venous Catheter Minocycline/Rifampin

480 ANtibiotic Impregnated Power Injectable; 2013.

481 22. Raad I, Hanna H, Maki D. Intravascular catheter-related infections: advances in diagnosis, 482 prevention, and management. The Lancet Infectious Diseases. 2007; 7(10): 645-57.

23. Universities of Leeds and Leicester. Paediatric Intensive Care Audit Network National Report $2011-2013 ; 2013$.

24. Slater A, Shann F, Pearson G. PIM2: a revised version of the Paediatric Index of Mortality. Intens Care Med. 2003; 29(2): 278-85.

487 25. Gray RJ. A class of K-sample tests for comparing the cumulative incidence of a competing risk. Ann Stat. 1988; 16(3): 1141-54.

26. Harron K, Mok Q, Parslow R, Muller-Pebody B, Gilbert R, Ramnarayan P. Risk of bloodstream infection in children admitted to paediatric intensive care units in England and Wales following emergency inter-hospital transfer. Intens Care Med. 2014; 40(12): 1916-23. catheters: a meta-analysis of randomized controlled trials. J Antimicrob Chemoth. 2007; 59(3): 35969.

28. Shah PS, Shah N. Heparin-bonded catheters for prolonging the patency of central venous catheters in children. Cochrane Database Syst Rev. 2014; 17(4): CD005983. monitoring of blood-stream infection in paediatric intensive care: a data linkage study. Intens Care Med. 2013; 39(6): 1080-7. 
500 30. Harron K, Woolfall K, Gamble C, Mok Q, Ramnarayan P, Gilbert R. Deferred consent for

501 randomised controlled trials in emergency paediatric care settings: evidence for trial design and 502 ethics committees. Pediatrics (in press). 
Figure 1: CONSORT flow diagram showing numbers of trial participants

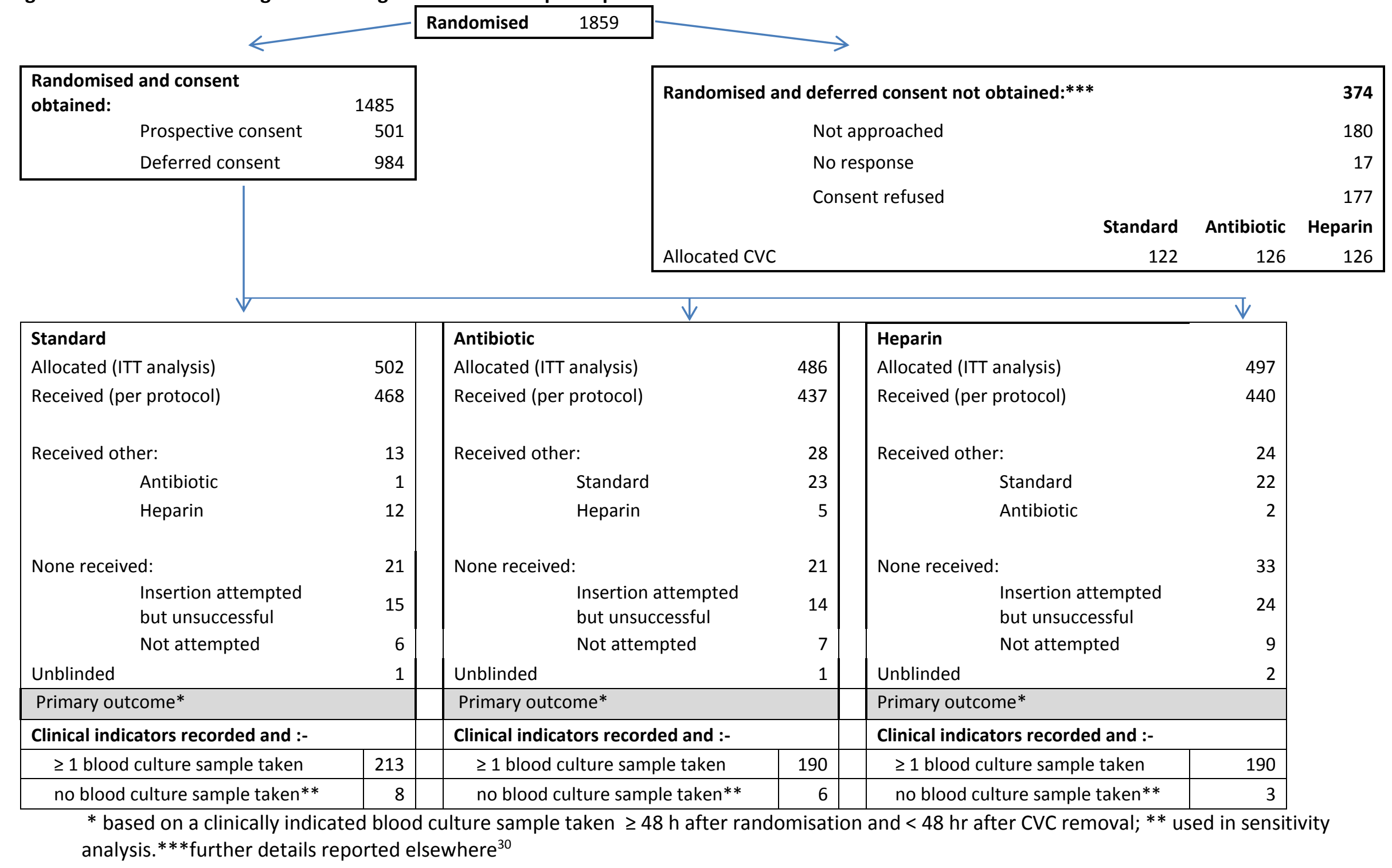


Figure 2: Kaplan-Meier curve for time to first BSI by CVC allocation (numbers show participants at risk and number of BSI events in brackets)

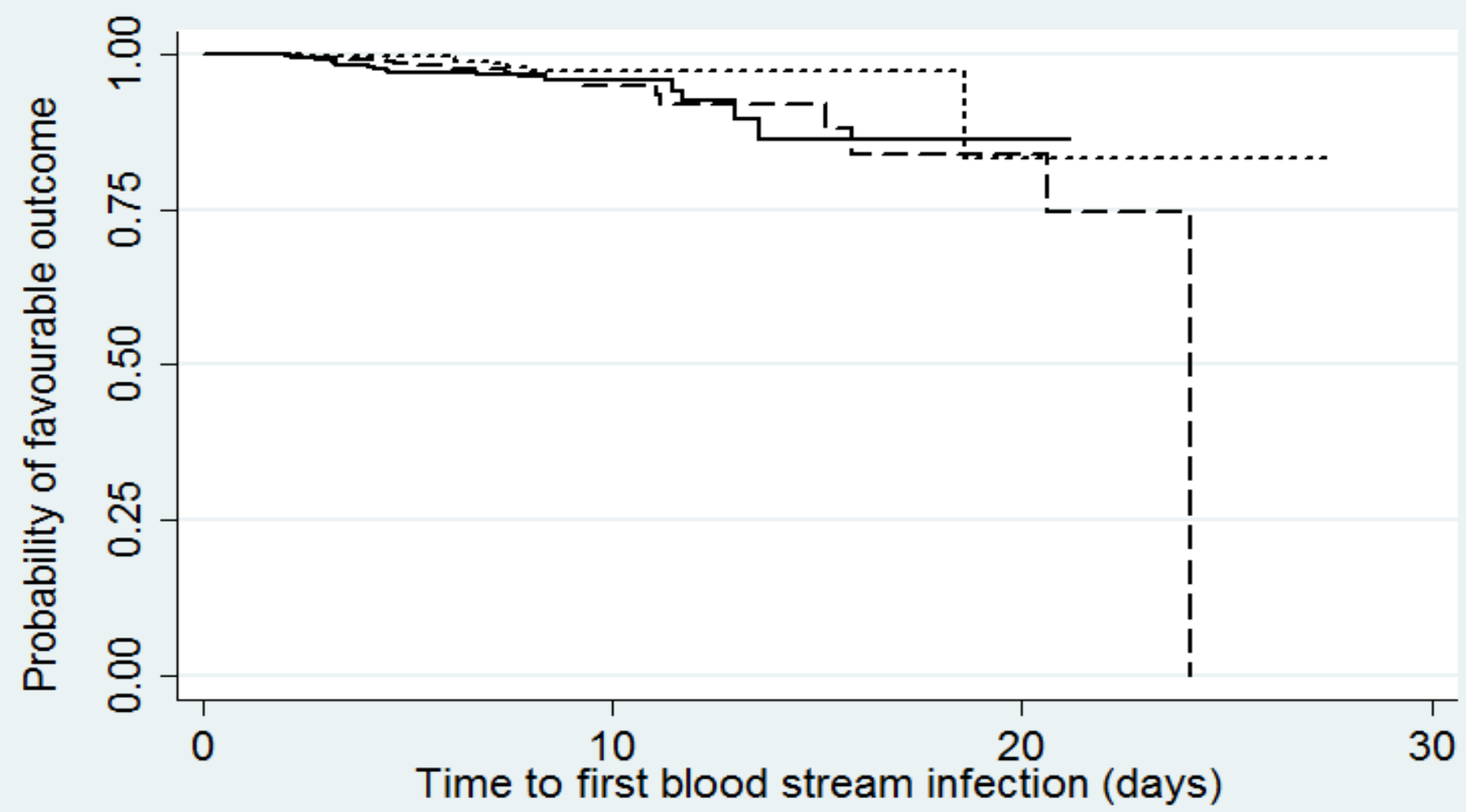

Number at risk

Antibiotic

465 (1) 427 (1) 244 (4) 113 (0) 56 (0) 19 (0) 9 (1) 3 (0) 3 (0) 3 (0) 2

Heparin

464 (4) 420 (7) 229 (2) 108 (2) 44 (2) 16 (0) 99 (0) 2 (0) 11 (0) 1

Standard

481 (3) 441 (4) 250 (4) 111 (3) 49 (0) 24 (2) 14 (1) 8 (1) 1 (0) 0

…....... Antibiotic Heparin - - - - Standard


Table 1: Baseline characteristics, clinical condition at randomisation and details of the intervention ( $n=$ number of participants)

\begin{tabular}{|c|c|c|c|c|c|c|c|}
\hline Patient characteristics & & $\begin{array}{r}\text { Stan } \\
n \\
502\end{array}$ & $\begin{array}{l}\text { lard } \\
\% \\
100 \\
\end{array}$ & $\begin{array}{r}\text { Anti } \\
n \\
486\end{array}$ & $\begin{array}{c}\text { jiotic } \\
\% \\
100\end{array}$ & $\begin{array}{r}\text { Hep } \\
n \\
497\end{array}$ & $\begin{array}{l}\text { arin } \\
\% \\
100\end{array}$ \\
\hline Emergency (deferred consent) & & 333 & 66.3 & 320 & 65.8 & 331 & 66.6 \\
\hline Elective (prospective consent) & & 169 & 33.7 & 166 & 34.2 & 166 & 33.4 \\
\hline Male & & 285 & 56.8 & 291 & 59.9 & 277 & 55.7 \\
\hline \multirow{4}{*}{ Age } & $<3$ months & 159 & 31.7 & 159 & 32.7 & 175 & 35.2 \\
\hline & 3-12 months & 129 & 25.7 & 123 & 25.3 & 116 & 23.3 \\
\hline & $1-10$ years & 174 & 34.7 & 154 & 31.7 & 174 & 35.0 \\
\hline & $11+$ years & 40 & 8.0 & 50 & 10.3 & 32 & 6.4 \\
\hline \multirow{4}{*}{ Weight at admission } & $<3 \mathrm{~kg}$ & 41 & 8.2 & 38 & 7.8 & 56 & 11.3 \\
\hline & $3-10 \mathrm{~kg}$ & 278 & 55.4 & 280 & 57.6 & 273 & 54.9 \\
\hline & $>10 \mathrm{~kg}$ & 183 & 36.5 & 166 & 34.2 & 168 & 33.8 \\
\hline & Missing & 0 & 0.0 & 2 & 0.4 & 0 & 0.0 \\
\hline Admitted for surgery & & 174 & 34.7 & 171 & 35.2 & 181 & 36.4 \\
\hline PICU assessment (from linked & ANet data) & 479 & 95.4 & 456 & 93.8 & 473 & 95.2 \\
\hline \multirow{9}{*}{ Primary reason for admission } & Cardiovascular & 235 & 49.1 & 233 & 51.1 & 250 & 52.9 \\
\hline & Endocrine/metabolic & 30 & 6.3 & 34 & 7.5 & 30 & 6.3 \\
\hline & Infection & 39 & 8.1 & 30 & 6.6 & 31 & 6.6 \\
\hline & Cancer & 9 & 1.9 & 6 & 1.3 & 8 & 1.7 \\
\hline & Respiratory & 102 & 21.3 & 86 & 18.9 & 84 & 17.8 \\
\hline & Neurological & 22 & 4.6 & 31 & 6.8 & 29 & 6.1 \\
\hline & Trauma & 18 & 3.8 & 10 & 2.2 & 18 & 3.8 \\
\hline & Other & 24 & 5.0 & 26 & 5.7 & 22 & 4.7 \\
\hline & Unknown & 0 & 0.0 & 0 & 0.0 & 1 & 0.2 \\
\hline \multirow{5}{*}{$\begin{array}{l}\text { Paediatric Index of Mortality } \\
\text { (PIM2) }\end{array}$} & $<1 \%$ & 54 & 11.3 & 48 & 10.5 & 48 & 10.1 \\
\hline & $1-5 \%$ & 264 & 55.1 & 236 & 51.8 & 247 & 52.2 \\
\hline & $5-<15 \%$ & 116 & 24.2 & 123 & 27.0 & 119 & 25.2 \\
\hline & $15-<30 \%$ & 34 & 7.1 & 31 & 6.8 & 39 & 8.2 \\
\hline & $30 \%+$ & 11 & 2.3 & 18 & 3.9 & 20 & 4.2 \\
\hline \multicolumn{2}{|c|}{ Clinical condition at randomisation } & 502 & 100.0 & 486 & 100.0 & 497 & 100.0 \\
\hline \multirow{4}{*}{$<72 \mathrm{~h}$ before randomised } & CVC in situ & 95 & 18.9 & 91 & 18.7 & 83 & 16.7 \\
\hline & Anticoagulants received & 50 & 10.0 & 59 & 12.1 & 61 & 12.3 \\
\hline & Antibiotics received & 286 & 57.0 & 276 & 56.8 & 284 & 57.1 \\
\hline & Positive blood culture & 40 & 8.0 & 25 & 5.1 & 36 & 7.2 \\
\hline \multirow{2}{*}{ At randomisation } & Infection suspected & 214 & 42.6 & 181 & 37.2 & 199 & 40.0 \\
\hline & Immune compromised & 44 & 8.8 & 31 & 6.4 & 29 & 5.8 \\
\hline CVC details (inserted CVCs) & & 481 & 95.8 & 465 & 95.7 & 464 & 93.4 \\
\hline \multirow[t]{2}{*}{ Deferred consent, CVC inserted } & & 314 & 65.3 & 301 & 64.7 & 302 & 65.1 \\
\hline & $\mathrm{ICU}$ & 276 & 57.4 & 264 & 56.8 & 259 & 55.8 \\
\hline \multirow[t]{2}{*}{ Inserted at same hospital } & Theatre & 5 & 1.0 & 4 & 0.9 & 7 & 1.5 \\
\hline & Other & 2 & 0.4 & 3 & 0.6 & 1 & 0.2 \\
\hline Inserted at other hospital* & $\mathrm{ICU}$ & 5 & 1.0 & 6 & 1.3 & 3 & 0.6 \\
\hline
\end{tabular}




\begin{tabular}{|c|c|c|c|c|c|c|c|}
\hline & Theatre & 3 & 0.6 & 8 & 1.7 & 7 & 1.5 \\
\hline & Other & 23 & 4.8 & 16 & 3.4 & 23 & 5.0 \\
\hline \multicolumn{2}{|l|}{ Missing } & 0 & 0.0 & 0 & 0.0 & 2 & 0.4 \\
\hline \multicolumn{2}{|c|}{ Prospective consent, CVC inserted } & 167 & 34.7 & 164 & 35.3 & 162 & 34.9 \\
\hline \multirow{3}{*}{ Inserted at same hospital } & $\mathrm{ICU}$ & 15 & 3.1 & 23 & 4.9 & 16 & 3.4 \\
\hline & Theatre & 152 & 31.6 & 141 & 30.3 & 144 & 31.0 \\
\hline & Other & 0 & 0.0 & 0 & 0.0 & 1 & 0.2 \\
\hline \multicolumn{2}{|l|}{ Triple lumen CVC } & 450 & 93.6 & 421 & 90.5 & 422 & 90.9 \\
\hline \multicolumn{2}{|c|}{ CVC inserted into femoral vein } & 253 & 52.6 & 217 & 46.7 & 235 & 50.6 \\
\hline
\end{tabular}

${ }^{*}$ CVCs were inserted by the retrieval team prior to transfer to PICU. 
Table 2: Endpoint frequency according to CVC allocation (ITT analyses) and CVC received (safety analyses). Values for $n$ refer to number of participants (\%) unless otherwise stated.

\begin{tabular}{|c|c|c|c|c|c|c|c|}
\hline & \multirow{2}{*}{\multicolumn{2}{|c|}{ Standard }} & \multirow{2}{*}{\multicolumn{2}{|c|}{ Antibiotic }} & \multirow{2}{*}{\multicolumn{2}{|c|}{ Heparin }} \\
\hline & & & & & & & \\
\hline \multicolumn{2}{|c|}{ Intention to treat analyses } & $N=502$ & $\%$ & $N=486$ & $\%$ & $N=497$ & $\%$ \\
\hline \multicolumn{8}{|c|}{ Primary outcome } \\
\hline \multirow{2}{*}{\multicolumn{2}{|c|}{$\begin{array}{l}\text { Bloodstream infection } \\
\text { Median time to first BSI in days (IQR) }\end{array}$}} & 18 & 3.59 & 7 & 1.44 & 17 & 3.42 \\
\hline & & 7.5 & $(4.5,11.2)$ & 6.9 & $(6.0,8.0)$ & 4.2 & $(3.1,8.4)$ \\
\hline \multirow{2}{*}{ Organism type } & non skin & $15^{\$}$ & 2.99 & 6 & 1.23 & 16 & 3.22 \\
\hline & skin & 3 & 0.60 & 1 & 0.21 & 1 & 0.20 \\
\hline \multirow{3}{*}{ Organism group* } & gram positive $\$ \$$ & 10 & 0.02 & 3 & 0.01 & 10 & 0.02 \\
\hline & gram negative & 6 & 0.01 & 4 & 0.01 & 5 & 0.01 \\
\hline & Candida & 2 & 0.00 & 0 & 0.00 & 3 & 0.01 \\
\hline \multicolumn{8}{|c|}{ Secondary outcomes } \\
\hline \multicolumn{2}{|c|}{ Catheter-related BSI } & 12 & 2.39 & 3 & 0.62 & 10 & 2.01 \\
\hline \multicolumn{2}{|c|}{$\begin{array}{l}\text { BSI rate per } 1000 \text { CVC days }(95 \% \mathrm{CI}) \\
\text { Number } / 1000 \text { days }\end{array}$} & $\begin{array}{c}8.24 \\
21 / 2.548\end{array}$ & $(4.72,11.77)$ & $\begin{array}{c}3.30 \\
8 / 2.389\end{array}$ & $(1.01,5.60)$ & $\begin{array}{c}8.79 \\
21 / 2.421\end{array}$ & $(5.03,12.55)$ \\
\hline \multicolumn{2}{|l|}{ Thrombosis } & 125 & 24.90 & 126 & 25.93 & 105 & 21.13 \\
\hline \multicolumn{2}{|c|}{ Median time to CVC removal in days (IQR) } & 4.28 & $(2.30,6.97)$ & 4.31 & $(2.13,7.0)$ & 4.20 & $(2.24,6.97)$ \\
\hline \multicolumn{2}{|c|}{ Mortality $\leq 30$ days after randomisation } & 42 & 8.37 & 39 & 8.02 & 28 & 5.63 \\
\hline \multicolumn{8}{|l|}{ Post-hoc analyses } \\
\hline \multicolumn{2}{|c|}{ Median time to PICU discharge in days (IQR) } & 5.1 & $(2.8,10.0)$ & 4.4 & $(2.2,9.3)$ & 4.9 & $(2.3,8.9)$ \\
\hline \multicolumn{2}{|c|}{ Median time to hospital discharge in days (IQR) } & 12.0 & $(6.4,25.6)$ & 12.0 & $(6.7,22.7)$ & 12.1 & $(6.4,22.5)$ \\
\hline \multicolumn{2}{|l|}{ Safety analyses } & $N=533$ & & $N=451$ & & $N=479$ & \\
\hline \multicolumn{2}{|c|}{ CVC related adverse events } & 9 & 1.69 & 14 & 3.10 & 8 & 1.67 \\
\hline \multicolumn{2}{|c|}{ Mortality $\leq 30$ days after randomisation } & 45 & 8.44 & 35 & 7.76 & 29 & 6.05 \\
\hline
\end{tabular}

$\$=$ includes 1 mixed BSI pathogen and skin organism; $\$ \$$ = includes $6 \mathrm{BSI}$ due to coagulase negative staphylococci ; ${ }^{*}=$ groups add to more than total due to multiple types of organisms isolated on same occasion in some patients; ${ }^{* *}$ composite measure of BSI including the primary outcome or a negative blood culture combined with a positive $16 \mathrm{~S}$ PCR result for bacterial DNA, removal of the CVC because of suspected infection, or a start of antibiotics or change in type of antibiotics on the same or next day. 
Table 3: Risk differences and relative effect measures by CVC allocated (ITT analyses). $\left(*=\right.$ rate ratio; ${ }^{\wedge}=$ risk ratio. Significant hazard ratios are in bold $(p<0.05)$

\begin{tabular}{|c|c|c|c|c|c|c|c|c|c|c|c|c|}
\hline & \multicolumn{3}{|c|}{$\begin{array}{l}\text { Any impregnated vs standard } \\
\text { (primary analysis) }\end{array}$} & \multicolumn{3}{|c|}{$\begin{array}{l}\text { Antibiotic vs standard } \\
\text { (secondary analysis) }\end{array}$} & \multicolumn{3}{|c|}{$\begin{array}{l}\text { Heparin vs standard } \\
\text { (secondary analysis) }\end{array}$} & \multicolumn{3}{|c|}{$\begin{array}{l}\text { Antibiotic vs heparin } \\
\text { (secondary analysis) }\end{array}$} \\
\hline & $\begin{array}{c}\text { risk } \\
\text { difference } \\
(95 \% \mathrm{Cl})\end{array}$ & $\begin{array}{c}\text { hazard ratio } \\
(95 \% \mathrm{Cl})\end{array}$ & $\begin{array}{c}\mathrm{p} \\
\text { value }\end{array}$ & $\begin{array}{c}\text { risk } \\
\text { difference } \\
(95 \% \mathrm{Cl})\end{array}$ & $\begin{array}{c}\text { hazard ratio } \\
(95 \% \mathrm{Cl})\end{array}$ & $\begin{array}{c}p \\
\text { value }\end{array}$ & $\begin{array}{c}\text { risk } \\
\text { difference } \\
(95 \% \mathrm{Cl})\end{array}$ & $\begin{array}{l}\text { hazard ratio } \\
(95 \% \mathrm{Cl})\end{array}$ & $\begin{array}{c}p \\
\text { value }\end{array}$ & $\begin{array}{c}\text { risk } \\
\text { difference } \\
(95 \% \mathrm{Cl})\end{array}$ & $\begin{array}{l}\text { hazard } \\
\text { ratio (95\% } \\
\text { Cl) }\end{array}$ & $\begin{array}{c}p \\
\text { value }\end{array}$ \\
\hline \multicolumn{13}{|l|}{ Primary outcome } \\
\hline $\begin{array}{l}\text { Time to first } \\
\text { bloodstream infection }\end{array}$ & $\begin{array}{c}-1.14 \\
(-3.04,0.75)\end{array}$ & $\begin{array}{c}0.71 \\
(0.37,1.34)\end{array}$ & 0.29 & $\begin{array}{c}-2.15 \\
(-4.09,-0.20)\end{array}$ & $\begin{array}{c}0.43 \\
(0.20,0.96)\end{array}$ & 0.04 & $\begin{array}{c}-0.17 \\
(-2.45,2.12)\end{array}$ & $\begin{array}{c}1.04 \\
(0.53,2.03)\end{array}$ & 0.90 & $\begin{array}{c}-1.98 \\
(-3.90,-0.06)\end{array}$ & $\begin{array}{c}0.42 \\
(0.19,0.93)\end{array}$ & 0.03 \\
\hline \multicolumn{13}{|l|}{ Secondary outcomes } \\
\hline CR-BSI & $\begin{array}{c}-1.07 \\
(-2.58,0.45)\end{array}$ & $\begin{array}{c}0.55^{\wedge} \\
(0.25,1.21)\end{array}$ & 0.13 & $\begin{array}{c}-1.77 \\
(-3.28,-0.27)\end{array}$ & $\begin{array}{c}0.25^{\wedge} \\
(0.07,0.90)\end{array}$ & 0.03 & $\begin{array}{c}-0.38 \\
(-2.20,1.44)\end{array}$ & $\begin{array}{c}0.84^{\wedge} \\
(0.36,1.96)\end{array}$ & 0.68 & $\begin{array}{c}-1.39 \\
(-2.81,0.02)\end{array}$ & $\begin{array}{c}0.30^{\wedge} \\
(0.08,1.11)\end{array}$ & 0.09 \\
\hline $\begin{array}{l}\text { Rate of BSI per } 1000 \\
\text { CVC days }\end{array}$ & $\begin{array}{c}-2.21 \\
(-6.36,1.94)\end{array}$ & $\begin{array}{c}0.73^{*} \\
(0.40,1.34)\end{array}$ & 0.31 & $\begin{array}{c}-4.94 \\
(-9.14,-0.73)\end{array}$ & $\begin{array}{c}0.40^{*} \\
(0.17,0.97)\end{array}$ & 0.04 & $\begin{array}{c}0.55 \\
(-4.60,5.70)\end{array}$ & $\begin{array}{c}1.07^{*} \\
(0.55,2.06)\end{array}$ & 0.85 & $\begin{array}{c}-5.49 \\
(-9.89,-1.08)\end{array}$ & $\begin{array}{c}0.38^{*} \\
(0.16,0.89)\end{array}$ & 0.03 \\
\hline $\begin{array}{l}\text { Time to first BSI or } \\
\text { culture negative } \\
\text { infection }\end{array}$ & $\begin{array}{c}-1.46 \\
(-5.90,2.98)\end{array}$ & $\begin{array}{c}0.95 \\
(0.75,1.20)\end{array}$ & 0.65 & $\begin{array}{c}-1.12 \\
(-6.26,4.03)\end{array}$ & $\begin{array}{c}0.95 \\
(0.72,1.23)\end{array}$ & 0.73 & $\begin{array}{c}-1.79 \\
(-6.87,3.30)\end{array}$ & $\begin{array}{c}0.95 \\
(0.73,1.25)\end{array}$ & 0.67 & $\begin{array}{c}0.67 \\
(-4.41,5.75)\end{array}$ & $\begin{array}{c}0.99 \\
(0.75,1.25)\end{array}$ & 0.93 \\
\hline $\begin{array}{l}\text { Time to CVC } \\
\text { thrombosis }\end{array}$ & $\begin{array}{c}-1.40 \\
(-6.02,3.22)\end{array}$ & $\begin{array}{c}0.98 \\
(0.79,1.22)\end{array}$ & 0.88 & $\begin{array}{c}1.03 \\
(-4.40,6.46)\end{array}$ & $\begin{array}{c}1.24 \\
(0.96,1.60)\end{array}$ & 0.49 & $\begin{array}{c}-3.77 \\
(-8.99,1.44)\end{array}$ & $\begin{array}{c}0.88 \\
(0.68,1.14)\end{array}$ & 0.34 & $\begin{array}{c}4.80 \\
(-0.50,10.10)\end{array}$ & $\begin{array}{c}1.25 \\
(0.96,1.62)\end{array}$ & 0.11 \\
\hline Time to CVC removal & & $\begin{array}{c}1.04 \\
(0.93,1.16)\end{array}$ & 0.53 & & $\begin{array}{c}1.02 \\
(0.90,1.17)\end{array}$ & 0.67 & & $\begin{array}{c}1.05 \\
(0.92,1.19)\end{array}$ & 0.51 & & $\begin{array}{c}0.99 \\
(0.87,1.13)\end{array}$ & 0.87 \\
\hline $\begin{array}{l}\text { Mortality } \leq 30 \text { days } \\
\text { after randomisation }\end{array}$ & & $\begin{array}{c}0.80^{\wedge} \\
(0.54,1.20)\end{array}$ & 0.28 & & $\begin{array}{c}0.96^{\wedge} \\
(0.61,1.51)\end{array}$ & 0.85 & & $\begin{array}{c}0.65^{\wedge} \\
(0.40,1.07)\end{array}$ & 0.09 & & $\begin{array}{c}1.46^{\wedge} \\
(0.86,1.11)\end{array}$ & 0.14 \\
\hline \multicolumn{13}{|l|}{ Post-hoc analyses } \\
\hline $\begin{array}{l}\text { Time to PICU } \\
\text { discharge }\end{array}$ & & $\begin{array}{c}1.08 \\
(0.97,1.20)\end{array}$ & 0.17 & & $\begin{array}{c}1.07 \\
(0.95,1.22)\end{array}$ & 0.27 & & $\begin{array}{c}1.08 \\
(0.96,1.23)\end{array}$ & 0.21 & & $\begin{array}{c}0.98 \\
(0.86,1.11)\end{array}$ & 0.73 \\
\hline $\begin{array}{l}\text { Time to hospital } \\
\text { discharge }\end{array}$ & & $\begin{array}{c}1.04 \\
(0.93,1.16)\end{array}$ & 0.47 & & $\begin{array}{c}1.03 \\
(0.91,1.16)\end{array}$ & 0.68 & & $\begin{array}{c}1.05 \\
(0.93,1.19)\end{array}$ & 0.42 & & $\begin{array}{c}0.98 \\
(0.87,1.11)\end{array}$ & 0.77 \\
\hline
\end{tabular}




\section{Supplementary material}

Appendix Table A1: Type of organism isolated from positive blood cultures including in the primary outcome

\begin{tabular}{|c|c|c|c|c|c|c|}
\hline \multirow[t]{2}{*}{ Category } & \multirow[t]{2}{*}{ Organism } & \multicolumn{5}{|c|}{ Type of CVC } \\
\hline & & Standard & Antibiotic & Heparin & $\begin{array}{l}\text { Antibiotic } \\
\text { or Heparin }\end{array}$ & Total \\
\hline \multicolumn{7}{|l|}{ Non-skin organisms } \\
\hline \multirow[t]{4}{*}{ Gram positive } & Staphylococcus aureus & 1 & 1 & 3 & 4 & 5 \\
\hline & Meticillin-resistant Staphylococcus aureus & 1 & 0 & 0 & 0 & 1 \\
\hline & Enterococcus spp. & 2 & 0 & 4 & 4 & 6 \\
\hline & Streptococcus spp & 2 & 1 & 1 & 2 & 4 \\
\hline \multirow[t]{7}{*}{ Gram negative } & Serratia marcescens & 1 & 1 & 0 & 1 & 2 \\
\hline & Pseudomonas aeruginosa & 2 & 1 & 1 & 2 & 4 \\
\hline & Gram negative bacillus & 1 & 0 & 1 & 1 & 2 \\
\hline & Enterobacteriaceae & 1 & 2 & 0 & 2 & 3 \\
\hline & Klebsiella spp. & 0 & 0 & 1 & 1 & 1 \\
\hline & Cellulomas spp. & 0 & 0 & 1 & 1 & 1 \\
\hline & Raoultella panticola and Enterobacter spp. & 1 & 0 & 0 & 0 & 1 \\
\hline Gram positive+Gram negative & Enterococcus spp. and Klebsiella pneumonia & 0 & 0 & 1 & 1 & 1 \\
\hline Fungi & Candida spp. & 2 & 0 & 3 & 3 & 5 \\
\hline \multicolumn{7}{|c|}{ Skin organisms (based on normal skin flora/commensals) } \\
\hline Gram positive & Coagulase-negative staphylococcus & 3 & 1 & 1 & 2 & 5 \\
\hline $\begin{array}{l}\text { Gram positive skin and gram } \\
\text { positive non-skin organisms }\end{array}$ & $\begin{array}{l}\text { Coagulase-negative staphylococcus and Enterococcus } \\
\text { spp. }\end{array}$ & 1 & 0 & 0 & 0 & 1 \\
\hline \multicolumn{2}{|l|}{ Total } & 18 & 7 & 17 & 24 & 42 \\
\hline
\end{tabular}


Appendix Table A2: Sensitivity analysis for the primary outcome (including clinically indicated BSI with no sample taken in time window) $\mathrm{N}=$ number of participants

\begin{tabular}{|c|c|c|c|c|c|c|c|c|c|}
\hline & \multirow[t]{2}{*}{$\stackrel{\mathrm{N}}{\text { randomised }}$} & \multicolumn{2}{|c|}{$\begin{array}{l}\text { Primary } \\
\text { outcome }\end{array}$} & \multicolumn{2}{|c|}{$\begin{array}{c}\text { Clinical } \\
\text { indication but } \\
\text { no sample } \\
\text { taken in time } \\
\text { window }\end{array}$} & \multicolumn{2}{|c|}{$\begin{array}{c}\text { Total } \\
\text { included in } \\
\text { sensitivity } \\
\text { analysis }\end{array}$} & \multirow[t]{2}{*}{$\begin{array}{l}\text { Hazard } \\
\text { ratio } \\
(95 \% \mathrm{Cl})\end{array}$} & \multirow[t]{2}{*}{$\begin{array}{c}\text { p- } \\
\text { value }\end{array}$} \\
\hline & & $\mathbf{N}$ & $\%$ & $\mathbf{N}$ & $\%$ & $\mathbf{N}$ & $\%$ & & \\
\hline $\begin{array}{l}\text { Any } \\
\text { impregnated } \\
\text { vs standard }\end{array}$ & 983 & 24 & 57.14 & 9 & 52.94 & 33 & 55.93 & $\begin{array}{c}0.67 \\
(0.39,1.15)\end{array}$ & 0.15 \\
\hline Standard & 502 & 18 & 42.86 & 8 & 47.06 & 26 & 44.07 & & \\
\hline $\begin{array}{l}\text { Antibiotic } \\
\text { vs standard }\end{array}$ & 497 & 7 & 16.67 & 6 & 35.29 & 13 & 22.03 & $\begin{array}{c}0.54 \\
(0.29,1.02)\end{array}$ & 0.06 \\
\hline $\begin{array}{l}\text { Heparin } \\
\text { vs standard }\end{array}$ & 486 & 17 & 40.48 & 3 & 17.65 & 20 & 33.90 & $\begin{array}{c}0.83 \\
(0.47,1.49)\end{array}$ & 0.54 \\
\hline $\begin{array}{l}\text { Antibiotic } \\
\text { vs heparin }\end{array}$ & & & & & & & & $\begin{array}{c}0.64 \\
(0.32,1.27)\end{array}$ & 0.20 \\
\hline Total & 1485 & 42 & & 17 & & 59 & & & \\
\hline
\end{tabular}


Appendix Table A3: Regression analysis for the primary outcome (time to first bloodstream infection)

\begin{tabular}{|c|c|c|c|c|c|}
\hline Analysis & Variable & Comparator & $\begin{array}{c}\text { Hazard } \\
\text { Ratio }\end{array}$ & $95 \% \mathrm{Cl}$ & p-value \\
\hline \multirow{3}{*}{ Primary } & Antibiotic or heparin CVC & standard & 0.71 & $(0.38,1.33)$ & 0.29 \\
\hline & Deferred consent & prospective & 0.87 & $(0.40,1.90)$ & 0.73 \\
\hline & Suspected infection & no suspected infection & 0.69 & $(0.33,1.42)$ & 0.31 \\
\hline \multirow{4}{*}{ Secondary } & Heparin CVC & standard & 1.05 & $(0.54,2.05)$ & 0.89 \\
\hline & Antibiotic CVC & standard & 0.40 & $(0.17,0.96)$ & 0.04 \\
\hline & Deferred consent & prospective & 0.87 & $(0.40,1.90)$ & 0.35 \\
\hline & Suspected infection & no suspected infection & 0.68 & $(0.33,1.40)$ & 0.30 \\
\hline \multirow{3}{*}{ Secondary } & Antibiotic CVC & heparin & 0.39 & $(0.16,0.95)$ & 0.04 \\
\hline & Deferred consent & prospective & 0.85 & $(0.30,2.45)$ & 0.76 \\
\hline & Suspected infection & no suspected infection & 0.99 & $(0.40,2.43)$ & 0.98 \\
\hline
\end{tabular}


Appendix Table A4: Number of children experiencing a BSI or culture negative indicators of a blood stream infection.

\begin{tabular}{|c|c|c|c|c|c|c|c|c|c|c|c|c|c|}
\hline \multirow[t]{3}{*}{ Treatment } & \multirow{3}{*}{$\begin{array}{l}\text { Number } \\
\text { randomised }\end{array}$} & \multicolumn{11}{|c|}{ Number experiencing BSI or culture negative blood stream infection } & \multirow[t]{3}{*}{ Total* } \\
\hline & & \multirow{2}{*}{$\begin{array}{l}\text { Primary } \\
\text { outcome }\end{array}$} & \multicolumn{10}{|c|}{ Any of the clinical indicators of infection and (negative) blood culture taken and } & \\
\hline & & & $\begin{array}{l}\text { High } \\
\text { bacterial } \\
\text { DNA load } \\
\text { from a PCR } \\
\text { positive } \\
\text { result only }\end{array}$ & $\begin{array}{l}\text { Change in } \\
\text { antibiotic } \\
\text { on same } \\
\text { day or next } \\
\text { day only }\end{array}$ & $\begin{array}{l}\text { ii. } \text { CVC } \\
\text { removal } \\
\text { for } \\
\text { infection } \\
\text { only }\end{array}$ & $\begin{array}{l}\text { Primary } \\
\text { outcome } \\
\text { and } \\
\text { removed } \\
\text { for } \\
\text { infection }\end{array}$ & $\begin{array}{l}\text { Primary } \\
\text { outcome } \\
\text { and } \\
\text { antibiotic } \\
\text { change }\end{array}$ & $\begin{array}{l}\text { Removed } \\
\text { for } \\
\text { infection } \\
\text { and } \\
\text { antibiotic } \\
\text { change }\end{array}$ & $\begin{array}{c}\text { PCR } \\
\text { positive } \\
\text { and } \\
\text { antibiotic } \\
\text { change }\end{array}$ & $\begin{array}{l}\text { Primary } \\
\text { outcome, } \\
\text { removed for } \\
\text { infection } \\
\text { and } \\
\text { antibiotic } \\
\text { change }\end{array}$ & $\begin{array}{l}\text { Removed } \\
\text { for } \\
\text { infection, } \\
\text { PCR } \\
\text { positive } \\
\text { and } \\
\text { antibiotic } \\
\text { change }\end{array}$ & $\begin{array}{c}\text { All } 4 \\
\text { criteria }\end{array}$ & \\
\hline Standard & 502 & 2 & 2 & 79 & 6 & 1 & 8 & 7 & 1 & 6 & 0 & 1 & 112 \\
\hline $\begin{array}{l}\text { Antibiotic } \\
\text { or Heparin }\end{array}$ & 983 & 4 & 2 & 135 & 19 & 0 & 12 & 24 & 1 & 7 & 0 & 1 & \\
\hline Antibiotic & 486 & 0 & 1 & 71 & 12 & 0 & 6 & 11 & 1 & 1 & 0 & 0 & 103 \\
\hline Heparin & 497 & 4 & 1 & 64 & 7 & 0 & 6 & 13 & 0 & 6 & 0 & 1 & 102 \\
\hline Total & 1485 & 6 & 4 & 214 & 25 & 1 & 20 & 31 & 1 & 13 & 0 & 2 & 317 \\
\hline
\end{tabular}

*Number of participants with BSI indicators in an exclusive descending hierarchy based on specificity of indicator for BSI (total $n=317$ ): BSI =42; PCR positive

$=5 ;$ CVC removed for infection $=56$; change or start of antibiotics same or next day $=214$ 
Appendix Table A5: Results of antibiotic resistance testing reported for 12 patients with a positive blood culture included in the primary outcome.

\begin{tabular}{|lll|}
\hline CVC allocation & \multicolumn{2}{c|}{ E test result } \\
\hline Standard & Minocycline & Rifampicin \\
-Colifom bacilli & Resistant & Resistant \\
-Enterococcus faecalis & Resistant & Resistant \\
-Serratia marcescens & Resistant & Resistant \\
-Staph aureus & Sensitive & Sensitive \\
-Meticillin resistant Staphylococcus & Sensitive & Sensitive \\
aureus & & \\
Antibiotic & & \\
-E.coli & Resistant & Resistant \\
-Staphylococcal spp & Resistant & Resistant \\
Heparin & & \\
-Klebsiella pneumoniae & Resistant & Resistant \\
-Klebsiella pneumoniae & Resistant & Resistant \\
-Staph aureus & Sensitive & Sensitive \\
-Coagulase negative staphylococci & Sensitive & Sensitive \\
-Enterococcus hirae and & Resistant & Sensitive \\
Coagulase negative staphylococci & Sensitive & Resistant \\
\hline
\end{tabular}


Appendix Figure 1: Diagram shows samples taken, positive cultures, and clinically indicated positive cultures in the primary outcome time window that meet the criteria for the primary outcome. *The non-skin organism was from a sample taken at 47 hours and 55 minutes after randomisation (POTW = primary outcome time window).

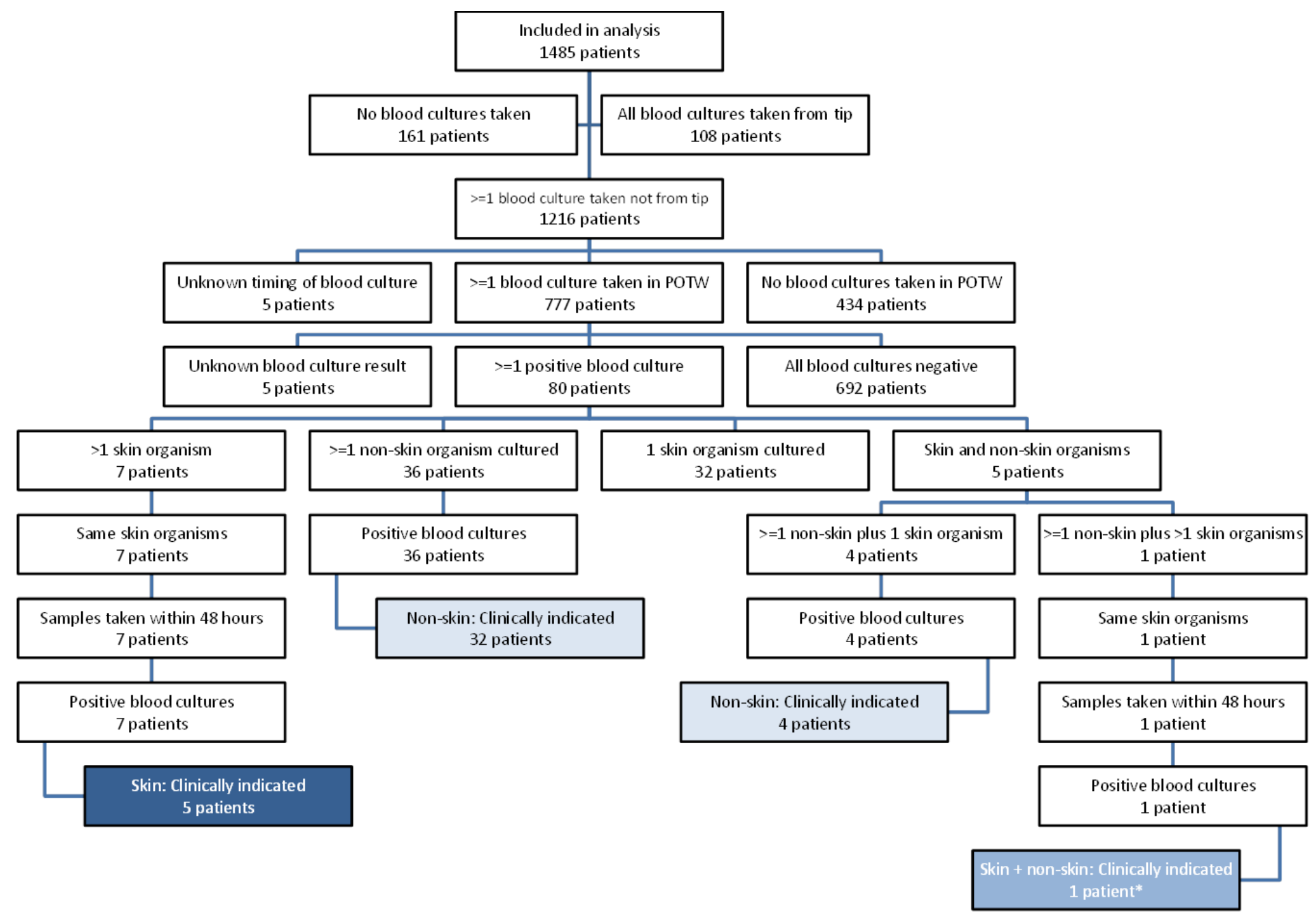


Appendix Figure 2: Number of children included in the primary outcome, the rate of BSI and catheter-related BSI according to time since randomisation

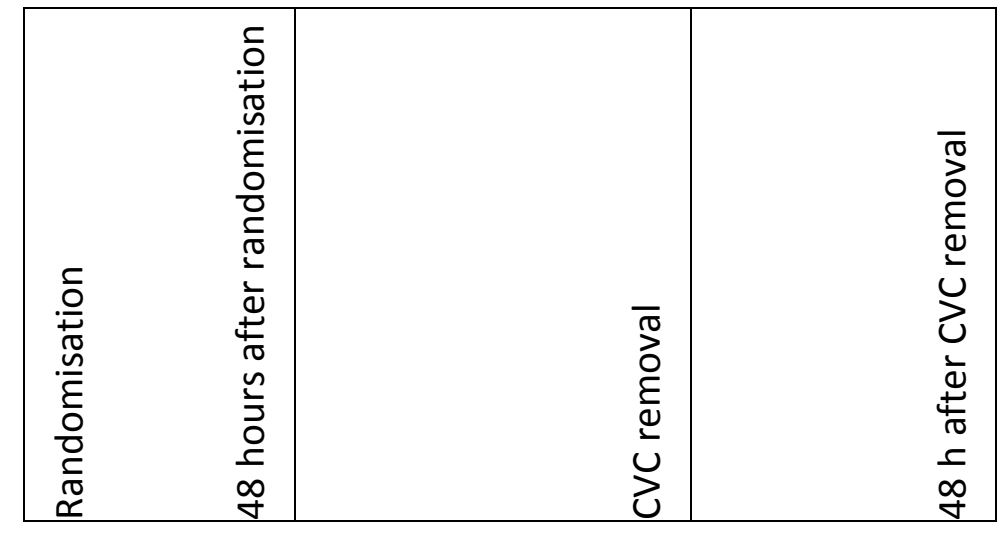

\begin{tabular}{|c|c|c|}
\cline { 2 - 3 } \multicolumn{1}{c|}{} & \multicolumn{2}{c|}{ Primary outcome of BSI } \\
\cline { 2 - 3 } \multicolumn{1}{c|}{} & $\mathrm{n}=40$ & $\mathrm{n}=2$ \\
\hline Rate of BSI per 1000 CVC-days & \\
\hline $\mathrm{n}=10$ & $\mathrm{n}=40$ & \\
\hline & Catheter-related BSI (CR-BSI) \\
\cline { 2 - 3 } & $\mathrm{n}=24$ & $\mathrm{n}=1$ \\
\hline
\end{tabular}

